\title{
Gênero e Representação Política nos Conselhos Gestores no Brasil*
}

\author{
Lígia Helena Hahn Lüchmann ${ }^{1}$ \\ Carla Almeida ${ }^{2}$ \\ Éder Rodrigo Gimenes ${ }^{2}$ \\ ${ }^{1}$ Universidade Federal de Santa Catarina (UFSC), Florianópolis, SC, Brasil. E-mail: \\ ligia@cfh.ufsc.br. \\ 'Universidade Estadual de Maringá (UEM), Maringá, PR, Brasil.
}

\section{INTRODUÇão}

s estudos sobre o tema da inclusão política, com destaque para a sub-representação política feminina, até então fortemente centrados no sistema eleitoral e nas instituições tradicionais do governo representativo, passaram a diversificar, no período mais recente, a maneira de formular o problema da presença/ausência de mulheres na política. Esse movimento se expressa em várias direções. Ele pode ser percebido, por exemplo, nos estudos sobre os impactos da entrada de ativistas feministas na burocracia estatal não pelo sistema eleitoral, mas por meio da criação de secretarias, ministérios e órgãos especializados em políticas para mulheres. Segundo algumas análises, as femocratas, como são chamadas, expressariam uma forma específica de institucionalização da presença feminina no Estado e um canal particular

\footnotetext{
* Este artigo é a segunda versão do trabalho apresentado no XXXIII Congresso da Latin American Studies Association (LASA), em maio de 2015, e está inserido no âmbito do projeto "Mudanças e permanências nos padrões de participação política no Brasil: análise longitudinal do envolvimento político dos brasileiros (1988-2013)", que tem o apoio do Programa de Cooperação Acadêmica da Coordenação de Aperfeiçoamento de Pessoal de Nível Superior (Capes). Agradecemos os comentários de Benjamin Goldfrank e dos pareceristas anônimos de DADOS - Revista de Ciências Sociais, bem como aos acadêmicos Milena Cristina Belançon, Gustavo Venturelli, Márcia Schaefer e Fernando Mezadri pela inestimável contribuição no levantamento de dados junto aos Conselhos.
}

DADOS - Revista de Ciências Sociais, Rio de Janeiro, vol. 59, no-3, 2016, pp. 789 a 822. 
de inclusão das demandas dos movimentos feministas no sistema político (Lovenduski, 2005; Bohn, 2010; Avelar, 2013). Em outra direção, podemos também ver indícios daquele movimento nos estudos que começam a prestar atenção nas potencialidades de inclusão política de mulheres promovidas pelas inovações institucionais criadas nas últimas décadas em vários países da América Latina, tais como os Conselhos Gestores, as Conferências Públicas e os Orçamentos Participativos no Brasil; os Consejos Municipales de Desarrollo Rural Sustentable no México, os Gabinetes de Participación Ciudadana na Nicarágua e os Consejos Comunales na Venezuela (Avelar, 2013; Zaremberg, 2015).

Este artigo pretende contribuir com essa vertente de estudos, dando continuidade a um trabalho anterior que chamava a atenção para o fato de que, se na esfera da representação política eleitoral a balança registra um peso altamente favorável para os homens, o mesmo não ocorre em outros espaços ou práticas de atuação política, como é o caso dos conselhos gestores de políticas públicas (Lüchmann e Almeida, 2010). Pesquisas sobre o perfil de representantes nessas instâncias apontam não apenas para a expressiva atuação feminina, como uma reversão - em especial no caso dos conselhos da área social - dos dados do perfil de gênero em comparação com a esfera da representação parlamentar, majoritariamente masculina. Naquele momento, argumentamos que a representação política intermediada por organizações da sociedade civil, como é o caso dos conselhos gestores, seria mais favorável às mulheres do que a intermediada por partidos políticos. Além disso, sugerimos que a acentuada presença desse grupo em conselhos também se explicava pela forte institucionalização dessas instâncias nas áreas sociais, tradicionalmente reconhecidas como um terreno de atuação feminina, dada a associação socialmente construída das mulheres à esfera da reprodução e dos homens à esfera da produção. No trabalho ora apresentado, exploramos o alcance desses argumentos comparando a presença dos gêneros ${ }^{1}$ em distintas áreas de políticas públicas, na representação governamental e na sociedade civil, e também nas diferentes esferas de governo: nacional, estadual e municipal.

Partimos do pressuposto de que os conselhos gestores de políticas públicas são importantes conquistas no plano da democratização do poder político no Brasil, na medida em que contam com a participação da sociedade civil no exercício de atribuições públicas no que diz respeito à formulação, implementação e fiscalização das políticas governamen- 
tais. Assim, a presença feminina nesses espaços é um indicador importante do interesse e da atuação política das mulheres, a despeito de sua baixa presença nos espaços de representação política eleitoral.

Essas diferenças na inclusão política das mulheres podem ser analisadas a partir de diferentes perspectivas. Um fator de peso diz respeito ao grau de exigências, ou dos custos envolvidos nos processos não apenas de recrutamento, mas de envolvimento pessoal. De fato, a atuação nos conselhos, embora requeira conhecimentos e habilidades, é bem menos exigente no que se refere à disponibilidade de tempo, de recursos financeiros, de articulações, negociações e de disputa de poder, o que inclui, no caso da representação eleitoral, a competição - nos e entre os partidos - a visibilidade, o discurso público e midiático, a formação de alianças e o enfrentamento com hostilidades que estão ancoradas em discursos poderosos de encobrimento do emocional apontado como de domínio feminino - frente ao racional - lido como fundamento do mundo masculino. Assim, os constrangimentos institucionais - por exemplo, a falta de apoio por parte dos partidos políticos - e culturais - que atribuem responsabilidades distintas e específicas para cada gênero - conformam uma realidade desigual na distribuição dos recursos que são fundamentais no exercício da disputa política.

No entanto, como veremos, os dados da representação conselhista por este recorte de gênero também apontam para diferenças importantes no interior desse campo. São exatamente essas diferenças que o artigo pretende abordar. Com base em um mapeamento junto aos conselhos das áreas de saúde, assistência social e meio ambiente, pretende-se, aqui, avaliar a maior ou menor presença feminina nos conselhos, reconhecendo, também para esses casos, a importância do cruzamento de variáveis explicativas que são decorrentes de dinâmicas e processos de cunho político-institucional e de caráter sociocultural.

Tendo em vista que os Conselhos são espaços de discussão e definição de políticas públicas nas diferentes áreas e setores governamentais, partilhamos da posição de que, assim como nas instituições de representação parlamentar, o maior equilíbrio da presença dos gêneros nesses espaços torna-se, em si, um critério fundamental para avaliar a capacidade democrática de inclusão, revelando o quanto essas estruturas ampliam e pluralizam os sujeitos, olhares e demandas sociais. De outra forma, entender a presença de gêneros nos Conselhos também 
nos permite avaliá-los enquanto marcadores importantes nas carreiras políticas das mulheres que conseguem passar pelo difícil filtro de gênero do sistema eleitoral brasileiro. Mais do que isso, nos permite pensar nas possibilidades de se avaliar em que medida a presença feminina nos espaços conselhistas nos ajudaria a compreender se há, de fato, influências de gênero nas pautas e orientações das diferentes políticas governamentais.

Diante disso, o artigo está dividido em quatro seções, além desta nota introdutória. Na próxima seção apresentamos brevemente os principais indicadores analíticos e os instrumentos metodológicos de coleta dos dados, justificando a escolha das três áreas conselhistas que são, aqui, objeto de investigação. Na segunda abordamos os conselhos gestores no Brasil, com destaque às características mais gerais dos conselhos das áreas de saúde, assistência social e meio ambiente e aos estudos que apontam a significativa inclusão feminina em espaços conselhistas. Na sequência, discutimos as bases teóricas que dão suporte às variáveis e indicadores utilizados na pesquisa, bem como apresentamos os resultados da mesma, de caráter exploratório. Uma breve sistematização desses achados será apresentada nas considerações finais, indicando a necessidade de se avançar (e refinar) na coleta de dados e informações tendo em vista aprofundar análises sobre a temática da inclusão política das mulheres.

Convém destacar que, além de contribuir para a ampliação dos estudos sobre gênero e representação política em instituições participativas, o trabalho adensa e combina fatores e variáveis analíticas buscando servir, ademais, para os estudos e reflexões que estão voltados para a dimensão da inclusão política de outras minorias sociais.

\section{NOTA METODOLÓGICA, HIPÓTESES E INDICADORES DA PESQUISA}

No âmbito das duas molduras explicativas apontadas anteriormente, selecionamos, para efeito da análise dos dados, alguns elementos que consideramos centrais para a configuração das diferenças nos dados sobre a presença de mulheres e homens nos conselhos, quais sejam: a) elementos de caráter institucional, como os desenhos institucionais dos conselhos e o nível federativo, contemplando as diferentes esferas de governo: municipal, estadual e federal; e b) elementos no campo sociocultural, como as respectivas áreas de políticas públicas e o perfil do 
associativismo e/ou das organizações da sociedade civil que ocupam assento nesses espaços.

Grosso modo, o desenho institucional diz respeito ao formato organizativo dos mesmos, como o conjunto de regras, critérios, espaços, normas, leis, que operacionalizam a participação e respondem, em boa medida, pela sua maior ou menor capacidade inclusiva e deliberativa. Para efeito deste artigo, os indicadores do desenho institucional mapeados foram: a composição do conselho (se paritário, se tem mais representantes do governo ou mais representantes da sociedade civil); o método de escolha dos conselheiros da sociedade civil; e a sua competência (se é consultivo ou deliberativo).

No que diz respeito às influências da esfera de governo, recupera-se aqui a tese de que a relação entre o aumento dos custos e a baixa participação impacta de forma mais importante o segmento feminino. No tocante à área do conselho, optou-se pela escolha das áreas da saúde, assistência social e meio ambiente, partindo da hipótese de que, se a área da assistência social é preponderantemente feminina, a do meio ambiente, por seu caráter mais técnico, tende a ser ocupada pelo segmento masculino. Os conselhos na área da saúde seriam mais equilibrados no que se refere à representação pelo recorte de gênero, seja pelo seu desenho institucional (maioria da representação da sociedade civil), seja pelo seu histórico de vínculo com organizações sociais que contam com significativa presença feminina. Além disso, essas três áreas contam com sistemas mais estruturados, com a presença de conselhos nas três esferas de governo, o que nos permite explorar o quanto a escala governamental interfere na composição dos gêneros nessas instâncias. Por fim, buscamos avaliar em que medida a dimensão da área também repercute no perfil associativo de homens e mulheres. Neste sentido, avançamos aqui no sentido de avaliar a pertinência das relações entre o perfil da sociedade civil e a composição por gênero no interior dos conselhos.

Os dados foram coletados a partir de um mapeamento realizado em distintas esferas de governo. Além daqueles referentes aos conselhos nacionais nas áreas consideradas, coletamos informações de um conjunto de estados e ainda de conselhos gestores existentes nos maiores municípios dessas unidades da Federação em termos de população, segundo dados oficiais do Censo 2010 do Instituto Brasileiro de Geografia e Estatística (IBGE). Sendo assim, nossa análise contempla 140 
conselhos gestores, sendo 105 municipais ( $75 \%$ do total), 32 estaduais $(22,9 \%$ do total) e 3 federais $(2,1 \%$ do total). Os dados, que apresentam a distribuição dos conselhos analisados, nos permitem inferir que, majoritariamente, a distribuição dos casos se concentrou próxima à proporcionalidade entre as três áreas de políticas selecionadas².

Tabela 1

Conselhos Gestores Analisados

\begin{tabular}{l|c|c|c|c}
\hline \multirow{2}{*}{ Esfera de Governo } & \multicolumn{3}{|c|}{ Área de Política Pública } & \multirow{2}{*}{ Total } \\
\cline { 2 - 4 } & Assistência Social & Saúde & Meio Ambiente & \\
\hline \multirow{2}{*}{ Municipal } & 33 & 37 & 35 & 105 \\
\hline \multirow{2}{*}{ Estadual } & $31,4 \%$ & $35,2 \%$ & $33,4 \%$ & $100,0 \%$ \\
\hline \multirow{2}{*}{ Nacional } & 11 & 10 & 11 & 32 \\
\hline \multirow{2}{*}{ Total } & $34,4 \%$ & $31,2 \%$ & $34,4 \%$ & $100,0 \%$ \\
\hline
\end{tabular}

Fonte: Pesquisa “Gênero e representação política nos Conselhos Gestores no Brasil” (2015).

Considerando os conselhos de assistência social, nosso banco de dados é composto por 45 casos (33 conselhos municipais, 11 estaduais e o nacional), a menor recorrência entre os conselhos municipais pesquisados. Em se tratando da área de saúde, reunimos dados de 37 conselhos municipais, do conselho federal e de 10 conselhos estaduais (totalizando 48 casos). Por fim, os conselhos da área de meio ambiente correspondem a 47 casos (35 municipais, 11 estaduais e o nacional), número expressivo de informações se considerarmos a ausência de obrigatoriedade de existência dos mesmos nos municípios ${ }^{3}$.

Sobre a composição do banco de dados, é salutar destacar que, ainda que este não seja composto por uma amostra representativa do universo de conselhos gestores das áreas analisadas, o que não nos permite inferências estatísticas, a quantidade e a diversidade local dos casos contemplados nos fornecem subsídios para examinar a sustentação de algumas expectativas teóricas em confronto com os dados empíricos.

\section{CONSELHOS GESTORES E PARTICIPAÇÃO FEMININA NO BRASIL}

Os conselhos gestores de políticas públicas são instâncias amparadas por legislação e responsáveis pela discussão e/ou deliberação de polí- 
ticas públicas em suas respectivas áreas de atuação. A partir da Constituição de 1988, tais instâncias tornaram-se obrigatórias em algumas áreas de políticas, como saúde, assistência social e criança e adolescente. Desde então, esse modelo veio se expandindo pelo sistema político brasileiro, tornando-se referência para um conjunto mais variado de políticas. Segundo sistematização realizada pela Secretaria Geral da República com base em dados do IBGE, temos hoje no Brasil 62.562 conselhos municipais em diferentes áreas de políticas públicas: saúde, educação, assistência social, preservação do patrimônio, meio ambiente, segurança alimentar, direitos do idoso, cultura, habitação etc. (Secretaria Geral da República, 2014).

Há, no entanto, muitas variações nessas instâncias, seja em termos do perfil das organizações da sociedade civil que atuam nesses espaços, da sua competência (se consultivo, deliberativo, fiscalizador e/ ou normativo), de como está previsto o equilíbrio entre representação governamental e societal (tripartite, paritário etc.), do montante de recursos disponíveis, entre outras especificidades e diferenças. Essas variações correspondem, em larga medida, aos diferentes arranjos institucionais que vigoram nas distintas áreas de políticas e ao histórico específico de institucionalização dos conselhos nesses arranjos. Nesse sentido, cabe apresentar alguns dos traços marcantes dos conselhos nas áreas investigadas.

De acordo com definição legal, os Conselhos na área da Saúde são instâncias colegiadas de caráter permanente e integrantes das estruturas governamentais, vinculados às respectivas secretarias (ou ministério) da área da saúde, com caráter deliberativo. São formados por $50 \%$ de usuários, $25 \%$ de trabalhadores e $25 \%$ de prestadores de serviço e gestores. Nesta área, temos um sistema conselhista, na medida em que essas regras gerais valem para todas as esferas de poder governamental. Os conselhos de saúde estão presentes em quase a totalidade dos municípios brasileiros e, segundo a Pesquisa de Informações Básicas Estaduais - Estadisc $2013^{4}$ (IBGE, 2014a), todos os 27 estados da Federação possuem uma Secretaria de Saúde exclusiva que é responsável pela gestão da saúde e que abriga, portanto, o Conselho desta área. A Estadisc 2013 verificou também que, quanto ao perfil de gênero dos gestores estaduais desta área, a maior parte $(81,5 \%)$ dos secretários é do sexo masculino. Para a esfera municipal, a pesquisa do IBGE apontou que $51,2 \%$ dos órgãos gestores da área da saúde são dirigidos por mulheres e $48,8 \%$ por homens (idem). 
Os Conselhos de Meio Ambiente são instâncias colegiadas compostas por representantes de organizações governamentais e não governamentais, com diferentes desenhos institucionais, de acordo com cada regimento nas diferentes esferas e unidades da Federação. Todos os estados da Federação contam com um Conselho Estadual de Meio Ambiente que está subordinado à secretaria da área, mas sua presença nos municípios não corresponde à mesma abrangência verificada em áreas como saúde e assistência social. Nesses dois casos, os conselhos estão presentes em $99 \%$ dos municípios do país, enquanto que no meio ambiente estão presentes em 67,9\% (Secretaria Geral da República, 2014). De acordo com dados do Instituto de Pesquisa Econômica Aplicada (Ipea) (2013), no que diz respeito à composição dos dirigentes governamentais dessa área, observamos que a participação feminina é baixa, já que, em 2013, dos 27 titulares da pasta, apenas 5 (18,5\%) eram do sexo feminino, contra $22(81,5 \%)$ do sexo masculino. Neste documento não encontramos dados sobre o perfil dos secretários municipais para essa área.

Seguindo o modelo da área da saúde, os conselhos da área da assistência social também configuram um sistema nacional formado por conselhos municipais, estaduais e federal que replicam as normativas nacionais no que diz respeito ao caráter, às finalidades e à composição dos mesmos. Aqui, diferentemente das outras duas áreas, a participação feminina entre titulares das Secretarias Estaduais de Assistência Social é maior, totalizando 13 das 27 unidades da Federação, o que corresponde a $48 \%$ dos gestores estaduais. No que se refere à gestão municipal, a predominância é feminina: em 17,7\% dos municípios que declararam ter órgão gestor de assistência social, os dirigentes dessa pasta são homens, enquanto que, em $82,2 \%$, são mulheres. Destas, $23 \%$ são primeiras-damas, ou seja, esposas de prefeitos (IBGE, 2014b).

Como se constata, há uma forte presença de homens na direção das secretarias estaduais das políticas investigadas e, ainda que em maior número comparada à saúde e meio ambiente, as mulheres não chegam a $50 \%$ das gestoras estaduais na assistência social. No que diz respeito à direção dos órgãos municipais da saúde, há um maior equilíbrio dos gêneros e, na assistência social, há uma acentuada predominância feminina.

As discrepâncias na presença dos gêneros encontradas nos cargos executivos estaduais se reproduzem também em outras instituições repre- 
sentativas. Considerando-se as eleições nacionais ocorridas desde a redemocratização, embora os brasileiros nesse período tenham escolhido, de forma inédita (por duas vezes), uma mulher para ocupar a Presidência da República, no parlamento as deputadas nunca passaram dos 10\% dos eleitos. Dados oficiais do Tribunal Superior Eleitoral (TSE) - referentes às eleições de 2014 - apontam que a porcentagem de mulheres eleitas para o cargo de deputada federal foi de apenas 9,9\%. Ainda nessas últimas eleições, no Senado Federal elas passaram a representar 13,6\% das cadeiras disponíveis nessa instância, e para as assembleias legislativas estaduais representaram apenas $11 \%$ do total de eleitos. $\mathrm{O}$ contraste é gritante quando consideramos que as mulheres representam $51 \%$ da população do país.

Esse acentuado desequilíbrio da presença dos gêneros nos postos centrais das instituições governamentais e/ou representativas, como se sabe, não é um fenômeno exclusivo brasileiro, mas uma marca da maioria das democracias contemporâneas e, por isso mesmo, vem motivando um intenso debate que questiona a capacidade das instituições vigentes de cumprir o ideal democrático de uma justa distribuição do poder entre os diversos grupos que compõem a sociedade. Como algumas análises afirmam, em sociedades complexas e plurais, quando as características dos indivíduos que têm acesso ao poder político são semelhantes em termos de sexo, cor ou recursos financeiros, os limites e os vieses da representação política ficam evidentes (Mota e Biroli, 2014).

Conforme Williams (1998), por exemplo, o pertencimento involuntário a um grupo, como nascer mulher ou homem, ou branco ou negro, delimita as oportunidades e os recursos que temos disponíveis no curso das nossas vidas. Isso significa que os custos individuais para a organização e a participação política variam de acordo com os pertencimentos grupais. Por isso, seria injusto considerar o indivíduo referência exclusiva para a definição dos princípios e dos critérios que organizam a distribuição da representação política na sociedade. Segundo a autora, as desvantagens e as discriminações a que estão submetidos os indivíduos pertencentes aos grupos marginalizados, reproduzidas por gerações, limitam significativamente suas condições de participar "como um igual" das instituições sociais e políticas. Uma representação política justa exige, portanto, o reconhecimento dessas desvantagens e instrumentos que a corrijam. 
Assim, os fortes desequilíbrios verificados na presença institucional dos grupos definidos por características como gênero, classe e etnia têm colocado no centro dos debates sobre a representação democrática a pertinência de se resgatarem os pressupostos da "representação descritiva", modelo de representação política que se preocupa com a pergunta: "quem representa - ou quem é o representante?". A evidência desse fenômeno pode ser constatada no significativo número de países que passaram a adotar alguma modalidade de cota para promover um maior equilíbrio dos gêneros nos legislativos. Assim, se até 1980 apenas 10 países possuíam cotas, a partir da década de 1990 as cotas apareciam em mais de 50 países e ao longo dos anos 2000 esse dispositivo já estava presente em mais de cem países (Krook, 2008).

Teóricas feministas tiveram um importante papel na construção de argumentos que advogam pela necessidade de reformas na representação política de modo a torná-la mais justa. Para Mansbridge (1999), por exemplo, existiriam quatro contextos ou circunstâncias que demandariam uma representação descritiva. Primeiro, os contextos de fragilidades institucionais. Neles, a adoção da representação descritiva poderia gerar um senso partilhado de responsabilidade e fortalecer as relações entre os indivíduos e o sistema político. Segundo, uma representação descritiva teria maiores chances de promover pontes comunicativas entre representantes e representados em contextos nos quais a desconfiança produzida por uma história de subordinação compromete a conexão necessária entre representantes e representados pertencentes a grupos diferentes. Para a autora, nessas situações, quando oriundos dos mesmos grupos, a comunicação entre representante e representado flui de maneira muito mais fácil. Terceiro, a representação descritiva pode prestar um bom serviço em contextos nos quais determinados interesses, embora já manifestos, ainda não estejam devidamente cristalizados e inseridos na agenda política. Uma representação descritiva, nesses casos, é mais promissora para captar e carrear tais interesses para as instituições. Em quarto lugar, a representação descritiva deve ser adotada para corrigir a percepção negativa que os indivíduos pertencentes a grupos marginalizados têm de si mesmos em função da experiência da exclusão e subordinação. Nesses casos, o pertencimento a um grupo subordinado carrega um significado negativo, gerando nos indivíduos a percepção de uma cidadania de segunda classe. A representação descritiva poderia subverter essa situação, promovendo uma autoimagem positiva, na qual os indivíduos passam 
a se enxergar como capazes de governar, de ocupar postos de poder e direção na sociedade.

Embora esse debate não esteja livre de ruídos e de divergências entre as próprias feministas, podemos identificar também um importante conjunto de autoras que defende a ideia de que a ausência de determinados grupos na política, como as mulheres, altera, de alguma maneira, o próprio resultado ou a qualidade da política. Ou seja, o "mensageiro" é parte daquilo que constitui a "mensagem", para usar os termos de Phillips (1991, 2001). Nesse sentido, o monopólio de alguns grupos na política - definidos a partir de pertencimentos, por exemplo, de gênero e etnia - constitui uma injustiça que deve ser reparada. De acordo com a autora:

Representação adequada é, cada vez mais, interpretada como implicando uma representação mais correta dos diferentes grupos sociais que compõem o corpo de cidadãos, e noções de representação "típica", "especular" ou "descritiva", portanto, têm retornado com força renovada. (Phillips, 2001:273; tradução livre)

Iris Young (2000) é outra teórica a argumentar que o conteúdo da representação pode ser impactado por "quem" é o agente da representação. Segundo ela, classe, gênero e etnia, por exemplo, posicionam hierarquicamente os indivíduos na estrutura social, sendo que o compartilhamento dessa posição pode gerar não necessariamente interesses e opiniões comuns, mas determinados "pontos de vista" sobre a sociedade, que ela denomina de "perspectiva". Pode-se dizer que a "perspectiva" é gerada, então, pelo lugar de onde nós enxergamos o mundo a nossa volta, sendo resultante de longos processos históricos que cristalizam as estruturas sociais. Para Young, a ausência ou precária presença de "determinados pontos de vista" nas instituições representativas produz uma injustiça, porque eles não são levados em conta no momento em que as decisões são tomadas. Afinal, na ausência desses pontos de vista, possivelmente não chegariam ao debate decisório a percepção de como determinadas decisões podem afetar grupos específicos, como mulheres, negros e trabalhadores. Assim, por exemplo, ainda que mulheres possam ser representadas adequadamente por homens em termos de opiniões e interesses, dificilmente um homem conseguiria representar a perspectiva específica das mulheres nos processos decisórios. Por isso, ao lado das outras formas de representação, seria justo reconhecer e incorporar uma representação por perspectiva. 
É nesse contexto que a composição dos conselhos gestores vem chamando a atenção, pois estes se tornaram uma importante oportunidade de inclusão política em espaços de discussão e definição de políticas públicas. Os conselhos ampliaram e pluralizaram o exercício da representação política, incorporando setores tradicionalmente excluídos da representação de base eleitoral, como negros, mulheres e indígenas. No caso mais específico das mulheres, ainda que a inclusão desse grupo, como no caso de outras minorias (Alencar et al., 2013), possa variar dependendo da área de política pública, pesquisas na esfera municipal mostraram que encontramos, em um grupo de conselhos, uma composição bem mais equilibrada entre os gêneros em comparação com as instâncias tradicionais de representação política (Lüchmann e Almeida, 2010).

Na esfera nacional, a pesquisa conduzida pelo Ipea (2013) com 21 conselhos de diferentes áreas encontrou, no total, uma composição de $63 \%$ de homens e $37 \%$ de mulheres. Ou seja, persiste a predominância masculina, mas ela é bem menos acentuada do que a encontrada nas instituições tradicionais de representação no caso brasileiro, que não têm ultrapassado a marca dos 15\%, se considerarmos todas as esferas de representação eleitoral (Câmaras Municipais, Assembleias Legislativas e Senado Federal). Além disso, constatamos que um número significativo de deputadas eleitas nas três últimas legislaturas teve passagem por conselhos gestores: na legislatura de 2003-2007, 48\% delas tinham participado de algum conselho, na de 2007-2011, 40\%, e na de 2011-2015, 34\%. Esses dados nos permitem dizer que os conselhos são marcas importantes também nas carreiras políticas das mulheres que conseguem passar pelo difícil filtro de gênero do sistema eleitoral brasileiro (Almeida, Lüchmann e Ribeiro, 2012).

Para Avelar (2013), talvez o ativismo feminino em associações e nos diversos mecanismos de interação entre sociedade civil e Estado criados desde a Constituição de 1988 - como conselhos, conferências, comissões, orçamentos participativos etc. - nos ajude a compreender os avanços legais importantes obtidos no período em termos de direitos das mulheres, em contraste com a sub-representação desse grupo no Legislativo.

Sem desconsiderar a importância desse debate que vem procurando compreender melhor as relações entre representação descritiva (quem 
representa? Ou quem é o representante?) e representação substantiva (o que e como representa?), vamos nos dedicar aqui apenas aos fatores que estão implicados com o primeiro tipo de representação. Partilhamos da posição de que o equilíbrio da presença dos gêneros nas instituições é, em si, um critério fundamental para avaliar a qualidade das democracias, porque, independentemente das posturas ideológicas individuais, a presença de mulheres na política é um critério revelador do quanto as estruturas de poder e a cultura de uma determinada sociedade estão democratizadas (Pinto e Moritz, 2009). Nesse sentido, nosso foco aqui não está no conteúdo substantivo da representação feminina ou, em outras palavras, no que as mulheres fazem enquanto representantes. Diferentemente, nosso interesse está em saber quais são as condições ou os fatores que favorecem a presença de mulheres em instâncias representativas.

Pretendemos contribuir para aprofundar o conhecimento dos fatores que favorecem e dos que atenuam as potencialidades que os conselhos gestores oferecem para incrementar a presença política de mulheres nos processos decisórios no Brasil. E porque nosso foco é esse, optamos por combinar dois critérios na seleção dos conselhos estudados. Como já mencionamos, de um lado, selecionamos conselhos de diferentes áreas de políticas públicas, o que nos possibilita avaliar o peso de variáveis culturais para a presença de mulheres nessas instâncias. De outro, conselhos que estejam razoavelmente estruturados nos sistemas de suas respectivas políticas, o que nos permite analisar com maior precisão os condicionantes institucionais daquela presença.

\section{DIMENSÕES INSTITUCIONAIS E SOCIOCULTURAIS NA COMPOSIÇÃO DO PERFIL DE GÊNERO DOS CONSELHOS GESTORES}

Como assinalado, este artigo registra e reforça a importância do cruzamento de variáveis explicativas que são decorrentes de dinâmicas e processos de cunho político-institucional e de caráter sociocultural. É por este registro que identificamos, no interior dessas molduras mais amplas, alguns elementos que consideramos centrais para a configuração das diferenças nos dados sobre a presença de mulheres e homens nos conselhos, quais sejam: os respectivos desenhos institucionais dos conselhos; o nível federativo, ou esfera de governo do conselho (municipal, estadual ou federal); a área de atuação dos conselhos e, final- 
mente, o tipo de associativismo que dá suporte à representação conselhista.

Os desenhos institucionais são resultantes de diversos fatores, variando de acordo com os objetivos, a composição dos atores sociais e governamentais, as correlações de forças e de interesses, o setor da política participativa e a sua inserção no sistema mais amplo da divisão de poderes governamentais. As regras que conformam o desenho institucional são importantes elementos para entendermos a maior ou menor capacidade de inclusão de setores que têm sido tradicionalmente excluídos dos espaços de formulação e de decisão de políticas públicas, seja pelos critérios e mecanismos de mobilização e de composição, constrangendo alguns setores e estimulando outros; seja pelas regras de formação das agendas; dos processos de escolha de representantes; dos espaços de participação, entre vários outros indicadores (Lüchmann, 2007; Borba e Lüchmann, 2007). O perfil dos participantes é, em boa dose, definido pelos seus respectivos desenhos institucionais, responsáveis, portanto, pela maior ou menor inclusão e pluralização da participação e da representação ali exercida. Regras relativas à composição e aos procedimentos de fala e debate também são importantes na avaliação da maior ou menor capacidade de influência e de vocalização dos diferentes atores participativos.

Neste artigo, os indicadores do desenho institucional mapeados foram: a composição do conselho (se paritário, se tem mais representantes do governo ou mais representantes da sociedade civil); o método de escolha dos conselheiros da sociedade civil; e a sua competência (se é consultivo ou deliberativo). Esses dados foram colhidos para os conselhos das três áreas de políticas investigadas, observando o critério da diferença de escala, como podemos visualizar na Tabela 2, a seguir.

Como podemos observar, não encontramos distinções no que diz respeito à competência dos conselhos. Nessas três áreas, nas três esferas de governo, os conselhos assumem função deliberativa. Vejamos mais detidamente os dois outros indicadores do desenho institucional, quais sejam, a paridade e o método de escolha dos conselheiros, nos quais é possível identificar um padrão segundo a área de política pública considerada, conforme mencionado anteriormente. 
Gênero e Representação Política nos Conselhos Gestores no Brasil

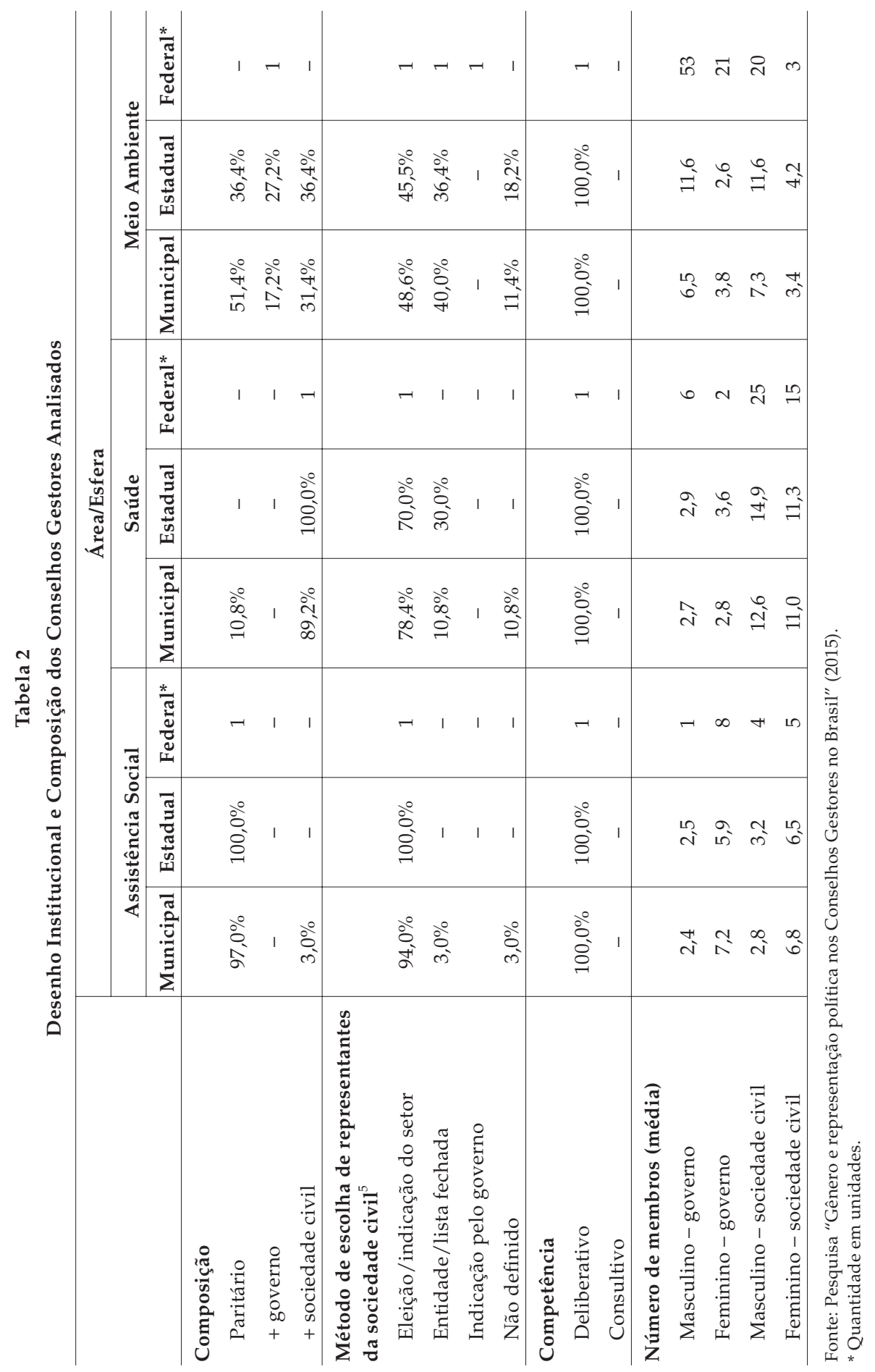

DADOS - Revista de Ciências Sociais, Rio de Janeiro, vol. 59, nº 3, 2016 
$\mathrm{Na}$ assistência social, os conselhos são paritários e predomina fortemente o método de definição da representação pela eleição/indicação por parte de organizações da sociedade civil. Na saúde, distintamente, a sociedade civil é predominante em relação ao governo na composição dos conselhos, mas aqui também prevalece o método de escolha de representantes pela eleição/indicação por parte da sociedade civil, ainda que haja presença também de conselhos onde os regimentos já trazem definidas as organizações que têm assento. No meio ambiente, há uma maior heterogeneidade: nos municípios, encontramos conselhos paritários em metade da amostra. Em 17,2\% deles, encontramos maior presença governamental e, em 31,4\%, maior presença da sociedade civil. Nos estados, a heterogeneidade se acentua um pouco mais quanto a esse indicador, e encontramos aí conselhos com maior representação governamental se comparados com os municípios, o que se reproduz na esfera federal. Identificamos ainda maior heterogeneidade nessa área quanto ao segundo indicador, já que temos os três métodos de escolha da representação da sociedade civil: eleição, lista fechada e indicação pelo governo.

Sobre a presença de homens e de mulheres, observamos o seguinte padrão nas três áreas: as mulheres predominam na assistência social, há um maior equilíbrio entre homens e mulheres na área da saúde, e os homens no meio ambiente. Assim, uma primeira conclusão a que chegamos ao compararmos elementos do desenho institucional com a presença dos gêneros é que conselhos com maior representação da sociedade civil não necessariamente incluem mais mulheres, como é o caso paradigmático da saúde, mas também em alguns casos do meio ambiente, que é uma área majoritariamente ocupada pelo segmento masculino.

No que diz respeito ao método de escolha, nossa hipótese sugere que pode fazer diferença se a escolha do conselheiro/a ocorre por meio de fóruns abertos da sociedade civil ou se é uma representação predefinida em regimentos, ou, ainda, resultante de indicação por outro segmento, como ocorre na área ambiental. Embora possa haver interveniência de outros fatores, a maior presença feminina nas organizações da sociedade civil, como atestado pelo estudo sobre as Fundações Privadas e Associações sem Fins Lucrativos no Brasil (IBGE/Ipea, 2010), indica maiores oportunidades de inclusão feminina quando o processo de escolha ocorre no interior deste campo. Ainda que possa- 
mos encontrar dificuldades para isolar este fator, os números da Tabela 2 são coerentes com esta hipótese. No caso do Conselho Nacional de Meio Ambiente, o único que conta com indicação da representação da sociedade civil realizada pelo governo, encontramos a maior disparidade na composição por gêneros: 20 homens e 3 mulheres.

Os dados acima, no entanto, indicam que esses elementos do desenho institucional não podem ser avaliados de forma separada da esfera de governo. Vale lembrar aqui que nos órgãos governamentais da saúde e assistência social essa influência foi detectada: há mais mulheres na direção dessas áreas nos municípios, se comparado com os estados. No caso dos conselhos, como mostra a Tabela 2, isso também se confirma, ou seja, a relação entre o aumento dos custos e a baixa participação impacta de forma mais importante as mulheres. Elas são em maior número na escala municipal e estadual, como também acontece nas conferências públicas, segundo os dados com os quais trabalhou Cunha (2012). Conforme sugere a autora, na esfera local parece haver maior possibilidade para as mulheres combinarem os compromissos da participação com os compromissos de cuidados com a família, os quais pesam mais sobre elas do que sobre os homens.

Entretanto, os nossos dados mostram algo mais se olharmos a área com maior representação feminina, a assistência social. Nela, podemos constatar que a intensidade da influência da escala sofre variações a depender do segmento: se sociedade civil ou governo. Assim, na assistência social, conforme aumenta a escala, a diferença entre mulheres e homens diminui na sociedade civil, enquanto que no governo a representação de mulheres continua bem maior. Na saúde, a presença dos gêneros é relativamente equilibrada nos municípios tanto no segmento governamental como no da sociedade civil. Nos conselhos estaduais, para o segmento governamental, esse equilíbrio se mantém, com pequena vantagem para as mulheres, mas para o segmento da sociedade civil a pequena vantagem se inverte para os homens. Já no conselho nacional dessa área, os homens predominam nos dois segmentos. E, por fim, vemos que, na política de meio ambiente, desde o nível municipal, há predominância masculina, mas que se acentua na escala nacional, sobretudo na representação da sociedade civil.

Essas conclusões são confirmadas pela Tabela 3, que apresenta dados apenas para a representação da sociedade civil, por área, nas três esferas de governo. 
Lígia Helena Hahn Lüchmann, Carla Almeida e Éder Rodrigo Gimenes

Tabela 3

Presença de Mulheres e Homens na Representação da Sociedade Civil por Esfera de Governo

\begin{tabular}{|c|c|c|c|c|c|c|c|c|c|c|}
\hline \multirow[b]{3}{*}{ Gênero } & \multicolumn{3}{|c|}{ Municipal } & \multicolumn{3}{|c|}{ Estadual } & \multicolumn{4}{|c|}{ Federal } \\
\hline & $\begin{array}{l}\text { Assis- } \\
\text { tência } \\
\text { Social }\end{array}$ & Saúde & $\begin{array}{c}\text { Meio } \\
\text { Ambi- } \\
\text { ente }\end{array}$ & $\begin{array}{l}\text { Assis- } \\
\text { tência } \\
\text { Social }\end{array}$ & Saúde & $\begin{array}{c}\text { Meio } \\
\text { Ambi- } \\
\text { ente }\end{array}$ & $\begin{array}{l}\text { Assis- } \\
\text { tência } \\
\text { Social }\end{array}$ & \multicolumn{2}{|c|}{ Saúde } & $\begin{array}{c}\text { Meio } \\
\text { Ambi- } \\
\text { ente }\end{array}$ \\
\hline & M F & $\mathbf{M}$ & M F & $\mathbf{M}$ & $\mathbf{M}$ & $\mathbf{M}$ & $\mathbf{M}$ & $\mathbf{M}$ & $\mathbf{F}$ & $\mathbf{M}$ \\
\hline $\mathrm{N}$ & $78 \quad 206$ & $473 \quad 415$ & $260 \quad 119$ & $\begin{array}{ll}35 & 71\end{array}$ & $148 \quad 114$ & 12746 & 5 & 25 & 15 & 20 \\
\hline$\%$ & $27,572,5$ & $53,3 \quad 46,7$ & $68,6 \quad 31,4$ & $33,0 \quad 67,0$ & $56,5 \quad 43,5$ & $73,426,6$ & $44,455,6$ & 62,53 & 37,5 & $87,0 \quad 13,0$ \\
\hline
\end{tabular}

Fonte: Pesquisa “Gênero e representação política nos Conselhos Gestores no Brasil” (2015).

Como podemos observar, apesar das variações por área, percebemos um movimento mais geral de ampliação da representação masculina conforme se avança na escala.

Até aqui os dados corroboram influências institucionais, sugerindo que determinados procedimentos e características podem facilitar ou dificultar uma maior presença feminina nesses espaços, como o método de escolha de conselheiros e a esfera de poder governamental. Além disso, reforçamos a importância de elementos socioculturais, em especial, a área de atuação dos conselhos. Como já ressaltado em outros estudos, nossos registros encontraram, para o caso da assistência social, muito mais mulheres tanto na representação da sociedade civil quanto na governamental. Por outro lado, vimos que os conselhos de saúde e de meio ambiente contam, seja com mais representação da sociedade civil (saúde) ou governamental (meio ambiente), com menor presença feminina nesses espaços. Esses registros da incidência de mulheres nos conselhos das áreas sociais corroboram as pesquisas que apontam forte correlação entre setor temático e gênero, sugerindo que determinadas áreas de políticas públicas, as de corte social, mobilizam as mulheres para o exercício da participação e da representação em detrimento de outras, que ainda parecem ser consideradas como o campo de domínio e de competência masculina. De maneira geral, os estudos indicam o maior investimento das mulheres nas questões sociais como os cuidados na área da saúde, de proteção às crianças e idosos, de atenção às famílias, além de políticas para as mulheres (Costa, 2001; Bolzendahl e Brooks, 2007).

Essa dimensão da área também repercute no perfil associativo de homens e mulheres. Com efeito, avançamos aqui no sentido de avaliar a pertinência das relações entre o perfil da sociedade civil e a com- 
posição por gênero no interior dos conselhos. Em outro trabalho (Lüchmann e Almeida, 2010), havíamos sugerido, baseadas em dados de conselhos municipais de áreas sociais, que a significativa presença das mulheres nos Conselhos Gestores explica-se, como uma primeira via interpretativa, pelo procedimento de escolha de representantes conselhistas, e que ocorre fundamentalmente pela intermediação de organizações da sociedade civil. Essa intermediação funcionaria como um filtro, na medida em que os conselheiros são, necessariamente, participantes de alguma organização e são escolhidos (eleitos ou indicados) por fóruns ou espaços de articulação social. Os vínculos com essas organizações e a maior facilidade, se comparado com o filtro operado pelo sistema eleitoral e mediado por partidos políticos, seriam elementos importantes para a inclusão feminina nesses espaços. No entanto, e em que pese a importância desse elemento do desenho institucional dos conselhos, percebemos diferenças significativas no perfil por gênero em organizações que estão representadas nos conselhos. Avaliamos, portanto, que faz diferença o tipo, ou o perfil, das organizações e instituições (tanto governamentais como sociais) que ocupam assento nos conselhos. Vejamos os dados referentes ao perfil - ou ao tipo ${ }^{6}$ - das organizações da sociedade civil que ocupam assento nos conselhos investigados.

Tabela 4

Associativismo Presente nos Conselhos

\begin{tabular}{l|c|c}
\hline Tipo de Associativismo & $\begin{array}{c}\text { Total } \\
\text { (n) }\end{array}$ & $\begin{array}{c}\text { Total } \\
\text { (\%) }\end{array}$ \\
\hline Mundo do trabalho & 645 & 29,8 \\
Movimentos sociais & 102 & 4,7 \\
Acadêmico & 137 & 6,3 \\
Empresarial/patronal & 250 & 11,6 \\
Socioassistencial & 285 & 13,2 \\
Assistencial religioso & 133 & 6,1 \\
Fóruns & 17 & 0,8 \\
Territorial/comunitário & 275 & 12,7 \\
Representantes de outros conselhos & 19 & 0,9 \\
Socioambiental & 105 & 4,9 \\
Outros & 37 & 1,7 \\
Sem identificação de entidade & 159 & 7,3 \\
\hline Total & $\mathbf{2 . 1 6 4}$ & $\mathbf{1 0 0 , 0}$ \\
\hline
\end{tabular}

Fonte: Pesquisa "Gênero e representação política nos Conselhos Gestores no Brasil” (2015). 
Conforme mostra a Tabela 4, nossa pesquisa classificou 2.164 associações que possuem assentos nos conselhos pesquisados. Destas, como discriminado na Tabela 5, 399 são dos conselhos de assistência social; 1.190 dos conselhos de saúde; e, finalmente, 575 dos conselhos de meio ambiente. Considerando os dados totais por associativismo, as associações do mundo do trabalho (os sindicatos de trabalhadores e associações profissionais) predominam nos conselhos estudados, seguidas pelo associativismo de caráter socioassistencial, territorial/comunitário e empresarial. O associativismo religioso e o do tipo acadêmico apresentam o mesmo peso na nossa amostra.

Tabela 5

Tipo de Associativismo por Área de Política

\begin{tabular}{l|cc|cc|cc|c}
\hline Tipo de Associativismo & $\begin{array}{c}\text { Assistência } \\
\text { Social }\end{array}$ & Saúde & $\begin{array}{c}\text { Meio } \\
\text { Ambiente }\end{array}$ & Total \\
\hline Mundo do trabalho & 64 & $16,0 \%$ & 458 & $38,5 \%$ & 123 & $21,4 \%$ & 645 \\
Movimentos sociais & 13 & $3,3 \%$ & 78 & $6,6 \%$ & 11 & $1,9 \%$ & 102 \\
Acadêmico & 4 & $1,0 \%$ & 41 & $3,4 \%$ & 92 & $16,0 \%$ & 137 \\
Empresarial/patronal & 5 & $1,3 \%$ & 93 & $7,8 \%$ & 152 & $26,4 \%$ & 250 \\
Socioassistencial & 107 & $26,8 \%$ & 164 & $13,8 \%$ & 14 & $2,4 \%$ & 285 \\
Assistencial religioso & 68 & $17,0 \%$ & 63 & $5,3 \%$ & 2 & $0,3 \%$ & 133 \\
Fóruns & 3 & $0,8 \%$ & 12 & $1,0 \%$ & 2 & $0,3 \%$ & 17 \\
Territorial/comunitário & 67 & $16,8 \%$ & 165 & $13,9 \%$ & 43 & $7,5 \%$ & 275 \\
Representantes de outros conselhos & 5 & $1,3 \%$ & 8 & $0,7 \%$ & 6 & $1,0 \%$ & 19 \\
Socioambiental & - & - & 3 & $0,3 \%$ & 102 & $17,7 \%$ & 105 \\
Outros & 4 & $1,0 \%$ & 8 & $0,7 \%$ & 25 & $4,3 \%$ & 37 \\
Sem identificação de entidade & 59 & $14,8 \%$ & 97 & $8,2 \%$ & 3 & $0,5 \%$ & 159 \\
\hline Total & $\mathbf{3 9 9}$ & $\mathbf{1 0 0 , 0} \%$ & $\mathbf{1 . 1 9 0}$ & $\mathbf{1 0 0 , 0} \%$ & $\mathbf{5 7 5}$ & $\mathbf{1 0 0 , 0} \%$ & $\mathbf{2 . 1 6 4}$ \\
\hline
\end{tabular}

Fonte: Pesquisa "Gênero e representação política nos Conselhos Gestores no Brasil" (2015).

A Tabela 5 considera os percentuais do tipo de associativismo por área de política pública. Conforme percebemos, na assistência social, como esperado, predomina o associativismo de caráter socioassistencial, seguido, nessa ordem, pelo associativismo assistencial religioso, territorial-comunitário e do mundo do trabalho, com destaque às associações e/ou conselhos de assistentes sociais. Na saúde, o predomínio é do associativismo do mundo do trabalho (sindical e associações profissionais), ao qual se seguem as associações de caráter territorial-comunitária, as de cunho socioassistencial e empresarial/patronal. Finalmente, nos conselhos de meio ambiente, o predomínio é do associativismo 
patronal-empresarial, seguido do associativismo do mundo do trabalho, do campo socioambiental e acadêmico. Observamos que, embora em menor número no plano geral, os movimentos sociais estão mais presentes na área da saúde. Contudo, cabe destacar o espaço ocupado pelo associativismo do mundo do trabalho no conjunto de conselhos, uma vez que, além de corresponder a praticamente $30 \%$ das organizações com assentos nos conselhos analisados, tomados em conjunto, este tipo de vínculo se destaca entre os mais recorrentes para as três áreas, observadas separadamente.

Por sua vez, a Tabela 6 apresenta os dados totais considerando-se o gênero da representação por tipo de associativismo, na qual percebemos o predomínio masculino na representação das seguintes categorias associativas: representantes de outros conselhos, empresarial/patronal, fóruns, mundo do trabalho e associativismo socioambiental. Vale destacar, nesses dados, a forte representação dos homens no associativismo empresarial/ patronal e no socioambiental, este último eminentemente constituído por Organizações Não Governamentais (ONGs). As mulheres são maioria no associativismo de caráter assistencial religioso e socioassistencial. Nos demais tipos, encontramos relativo equilíbrio na presença dos gêneros.

Tabela 6

Tipo de Associativismo por Gênero

\begin{tabular}{l|cc|cc|c}
\hline Tipo de Associativismo & \multicolumn{2}{|c|}{ Masculino } & \multicolumn{2}{|c|}{ Feminino } & Total \\
\hline Mundo do trabalho & 372 & $\mathbf{5 7 , 7} \%$ & 273 & $42,3 \%$ & 645 \\
Movimentos sociais & 54 & $52,9 \%$ & 48 & $47,1 \%$ & 102 \\
Acadêmico & 65 & $47,4 \%$ & 72 & $52,6 \%$ & 137 \\
Empresarial/patronal & 183 & $\mathbf{7 3 , 2} \%$ & 67 & $\mathbf{2 6 , 8 \%}$ & 250 \\
Socioassistencial & 127 & $44,6 \%$ & 158 & $\mathbf{5 5 , 4} \%$ & 285 \\
Assistencial religioso & 49 & $36,8 \%$ & 84 & $\mathbf{6 3 , 2} \%$ & 133 \\
Fóruns & 11 & $\mathbf{6 4 , 7} \%$ & 6 & $35,3 \%$ & 17 \\
Territorial/comunitário & 144 & $52,4 \%$ & 131 & $47,6 \%$ & 275 \\
Representantes de outros conselhos & 15 & $\mathbf{7 8 , 9} \%$ & 4 & $21,1 \%$ & 19 \\
Socioambiental & 65 & $\mathbf{6 1 , 9} \%$ & 40 & $38,1 \%$ & 105 \\
Outros & 20 & $\mathbf{5 4 , 1 \%}$ & 17 & $45,9 \%$ & 37 \\
Sem identificação de entidade & 65 & $40,9 \%$ & 94 & $59,1 \%$ & 159 \\
\hline Total & $\mathbf{1 . 1 7 0}$ & $\mathbf{5 4 , 1} \%$ & $\mathbf{9 9 4}$ & $\mathbf{4 5 , 9 \%}$ & $\mathbf{2 . 1 6 4}$ \\
\hline
\end{tabular}

Fonte: Pesquisa "Gênero e representação política nos Conselhos Gestores no Brasil" (2015). 
Já a Tabela 7 possibilita detalhar essa análise considerando o cruzamento dos dados de gênero e associativismo por área de política pública. Como podemos observar, na área da assistência social a presença das mulheres se destaca nos seguintes tipos associativos: socioassistencial, territorial/comunitário, mundo do trabalho - com destaque, como assinalado anteriormente, para o campo dos profissionais de assistência social -, e assistencial religioso. Já na área da saúde, embora também identifiquemos uma importante presença feminina no associativismo do mundo do trabalho, os homens ocupam maior representação nesta categoria, assim como também são maioria no associativismo territorial/comunitário. No caso da área do meio ambiente, os dados acusam, como ressaltado anteriormente, uma correlação significativa entre gênero masculino e associativismo do tipo empresarial/patronal, do mundo do trabalho e territorial/comunitário.

Tabela 7

Tipo de Associativismo por Área e Gênero

(\% por Área)

\begin{tabular}{l|cc|cc|cc}
\hline \multirow{2}{*}{ Tipo de Associativismo } & \multicolumn{3}{|c|}{ Assistência Social } & \multicolumn{2}{|c|}{ Saúde } & \multicolumn{2}{c}{ Meio Ambiente } \\
\cline { 2 - 7 } & $\mathbf{M}$ & $\mathbf{F}$ & $\mathbf{M}$ & $\mathbf{F}$ & $\mathbf{M}$ & $\mathbf{F}$ \\
\hline Mundo do trabalho & 3,0 & $\mathbf{1 3 , 0}$ & $\mathbf{2 2 , 9}$ & 15,5 & $\mathbf{1 5 , 1}$ & 6,3 \\
Movimentos sociais & 2,3 & 1,0 & 3,2 & 3,4 & 1,2 & 0,7 \\
Acadêmico & 0,0 & 1,0 & 1,2 & 2,3 & 8,9 & 7,1 \\
Empresarial/patronal & 0,0 & 1,3 & 4,4 & 3,4 & $\mathbf{2 2 , 8}$ & 3,7 \\
Socioassistencial & 8,0 & $\mathbf{1 8 , 8}$ & 7,0 & 6,8 & 2,1 & 0,3 \\
Assistencial religioso & 6,0 & $\mathbf{1 1 , 0}$ & 1,9 & 3,4 & 0,3 & 0,0 \\
Fóruns & 0,8 & 0,0 & 0,6 & 0,4 & 0,2 & 0,2 \\
Territorial/comunitário & 3,5 & $\mathbf{1 3 , 3}$ & $\mathbf{8 , 3}$ & 5,5 & 5,4 & 2,1 \\
Representantes de outros conselhos & 0,8 & 0,5 & 0,6 & 0,1 & 0,9 & 0,2 \\
Socioambiental & 0,0 & 0,0 & 0,2 & 0,1 & $\mathbf{1 1 , 0}$ & 6,8 \\
Outros & 0,0 & 1,0 & 0,4 & 0,3 & 2,6 & 1,7 \\
Sem identificação de entidade & 5,0 & 9,8 & 3,6 & 4,5 & 0,3 & 0,2 \\
\hline Total & $\mathbf{2 9 , 3}$ & $\mathbf{7 0 , 7}$ & $\mathbf{5 4 , 3}$ & $\mathbf{4 5 , 7}$ & $\mathbf{7 0 , 8}$ & $\mathbf{2 9 , 2}$ \\
\hline
\end{tabular}

Fonte: Pesquisa "Gênero e representação política nos Conselhos Gestores no Brasil" (2015).

Os dados acompanham os estudos que indicam que, embora seja cada vez mais frequente a participação feminina em sindicatos e associações econômicas e políticas, permanece ainda muito forte o vínculo com organizações sociais relacionadas com o mundo familiar, comuni- 
tário e religioso, diferente do vínculo associativo masculino, mais próximo da esfera política institucional, do mundo do trabalho e do lazer (Norris e Inglehart, 2003; Caiazza e Putnam, 2005; Sacchet, 2009). No caso do Brasil, se tomarmos como base o estudo das Fundações Privadas e Associações sem Fins Lucrativos no Brasil (IBGE/Ipea, 2010), percebemos que as mulheres são maioria na atuação associativa do país, com algumas variações. Os dados da pesquisa, realizada em 2010, apontam para a predominância das mulheres no setor sem fins lucrativos: elas representam $62,9 \%$ do pessoal ocupado assalariado.

O estudo também aponta as variações na distribuição de homens e mulheres de acordo com as áreas de atuação. No caso do associativismo religioso, temos $38,7 \%$ de homens contra $61,3 \%$ de mulheres atuando neste campo. Os dados demonstram que, também na área do meio ambiente e proteção animal, as mulheres superam os homens, com 55,6\% contra $44,4 \%$ de presença masculina. Esses dados sugerem que, mesmo que haja certa predominância feminina em organizações de meio ambiente (em contraste com a predominância masculina nos conselhos dessa área), os homens, embora minoritários na composição dos grupos e equipes de suas organizações, acabam assumindo os cargos de direção e de representação das mesmas, o que explicaria a sua maior presença na representação das ONGs que ocupam os conselhos da área.

No que diz respeito particularmente à área da saúde, pelo menos três elementos precisam ser considerados aqui para se avançar na compreensão acerca da representação dos gêneros nos conselhos desta área para o segmento da sociedade civil. Em primeiro lugar, a complexidade e a heterogeneidade das organizações que ocupam representação nesses conselhos, com destaque para os profissionais de saúde e os prestadores de serviços, a exemplo de associações, federações e confederações de comércio, indústria e instituições de saúde (clínicas e hospitais), e que são, em boa medida, representadas pelo gênero masculino. Em segundo lugar, o contraste verificado entre, de um lado, o relativo equilíbrio dos gêneros nos conselhos municipais e estaduais desta área para a representação da sociedade civil e, de outro, a acentuada presença de mulheres nas organizações sociais de saúde, conforme mostram os dados do IBGE/Ipea ${ }^{7}$. Esse contraste pode ser explicado, em parte, pela estratégia adotada por uma parcela dos movimentos de mulheres na década de 1990, os quais, como apontado por Costa (2009), parecem ter feito uma opção pelo ativismo institucional junto 
ao Ministério da Saúde, como assessoras de programas para mulheres, configurando o que a bibliografia denomina, como mencionamos anteriormente, femocratas (Lovenduski, 2005; Bohn, 2010; Avelar, 2013). Daí a precária presença desses movimentos nos órgãos de controle municipais e estaduais.

Segundo Costa (2009), informações do Sistema Nacional sobre Conselhos e Conselheiros da Saúde (relativas ao ano de 2007) mostraram que apenas $0,23 \%$ das entidades representantes de usuários nos conselhos dessa área eram relacionadas a temáticas femininas. Como terceiro elemento, sugerimos também que a criação dos conselhos específicos para políticas de mulheres tem mobilizado as organizações feministas e canalizado, assim, seu engajamento político para essas instâncias. De acordo com dados do IBGE sistematizados pela Secretaria-Geral da República, 17,5\% dos municípios brasileiros já contam com conselhos nessa área (Secretaria-Geral da República, 2014). A difusão de conselhos de direitos das mulheres pelo sistema político brasileiro contou com o incentivo do Plano Nacional para Políticas de Mulheres, de 2004.

Além disso, gostaríamos também de chamar a atenção para as diferenças nos perfis organizacionais - em termos de escopo e escala - das associações que atuam nos conselhos. É possível sugerir que o tipo de organização de base (religiosa, assistencial e comunitária) que fornece o suporte da significativa presença feminina nos conselhos municipais, na maioria dos casos, não tem abrangência para esferas estaduais e/ ou nacional. Assim, se a representação de trabalhadores e profissionais desta área adensa a população de conselheiras nos conselhos de assistência social, com destaque para a esfera nacional, por outro lado, as organizações sociais que têm assento nos conselhos municipais, em boa medida, não têm ramificações para além da esfera local. A Tabela 8 apresenta os dados relativos à presença das associações por esfera de governo.

Embora as variações suscitem maiores cuidados em qualquer tentativa de generalização, alguns dados chamam a atenção. Em primeiro lugar, o crescimento da presença de movimentos sociais da esfera local para a nacional, em todas as três áreas da política. Compreensivelmente, percebe-se a ausência, em especial na esfera federal, das associações de base territorial. Por último, a forte presença de ONGs na área ambiental e das associações religiosas na área da assistência social na esfera 
Gênero e Representação Política nos Conselhos Gestores no Brasil

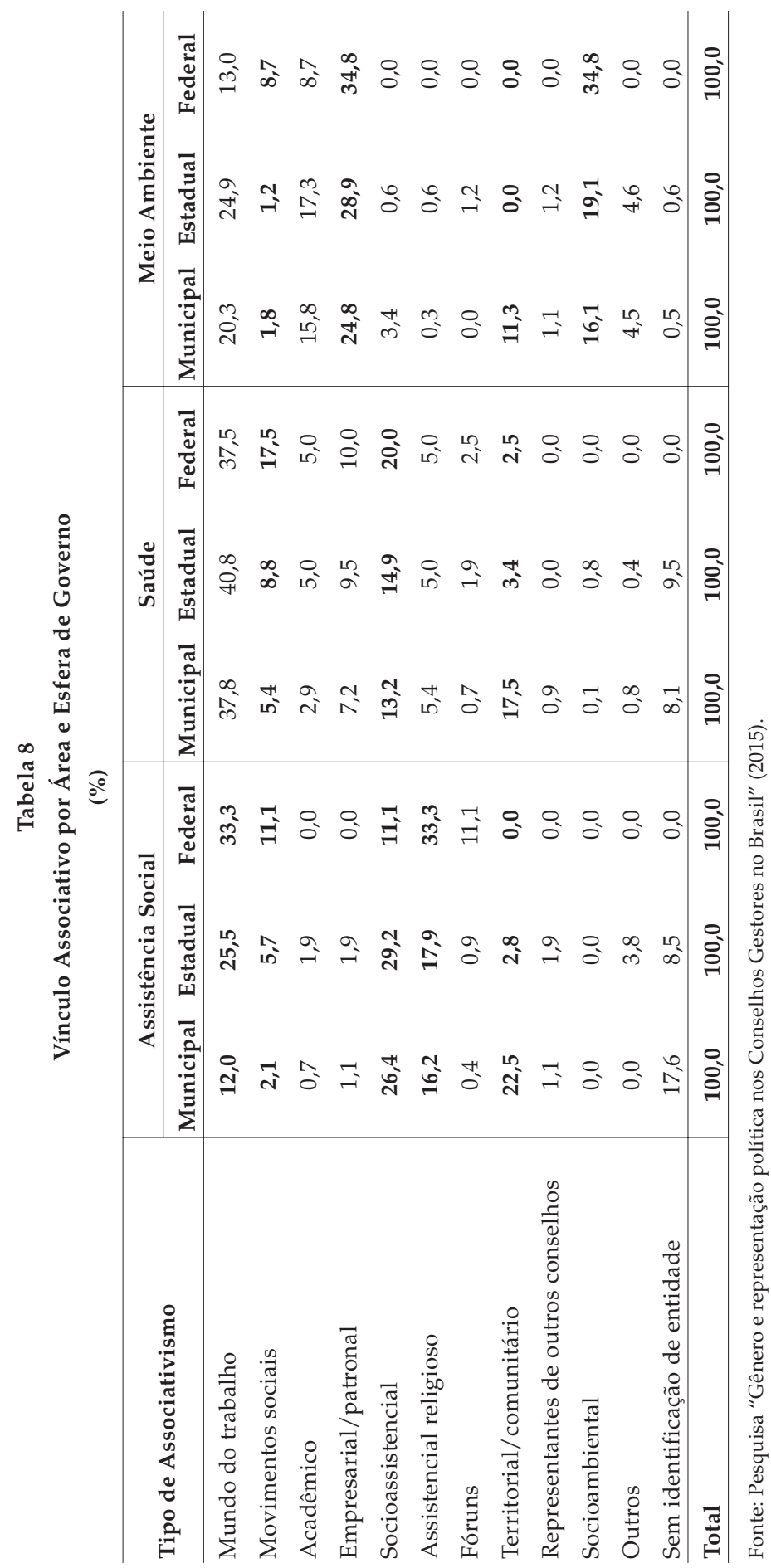

DADOS - Revista de Ciências Sociais, Rio de Janeiro, vol. 59, nº 3, 2016 
nacional. Da mesma maneira como ocorre com os sindicatos e associações profissionais, muitas ONGs e organizações religiosas, em especial as católicas, apresentam maior porte de recursos e de estrutura organizacional.

\section{CONSIDERAÇÕES FINAIS}

Este artigo teve por objetivo avaliar, a partir de um mapeamento realizado junto aos conselhos das áreas de saúde, assistência social e meio ambiente, os elementos que julgamos centrais para a configuração das diferenças nos dados sobre a presença de mulheres e homens nos conselhos de políticas públicas. São eles: os respectivos desenhos institucionais dos conselhos; o nível federativo, ou a esfera de governo do conselho: se municipal, estadual ou federal; a área de atuação dos conselhos; e, finalmente, o perfil do associativismo e/ou das organizações e setores que ocupam esses espaços. Neste sentido, o trabalho reforça a importância do cruzamento de variáveis explicativas que são decorrentes de dinâmicas e processos de cunho político-institucional e de caráter sociocultural.

Nossos dados corroboraram as associações já detectadas por outras pesquisas entre, de um lado, temáticas de políticas públicas e escalas de governo e, de outro, maior ou menor presença de mulheres. Encontramos diferenças do perfil por gênero entre os conselhos das áreas de assistência social (mulheres são maioria), saúde (maior equilíbrio entre homens e mulheres) e meio ambiente (mulheres são minoria), como também detectamos que as mulheres estão mais presentes nas esferas municipais e estaduais.

Buscando aprofundar um pouco mais o conhecimento sobre essas correlações, os resultados destacam que a influência da escala de governo pesa de forma diferente nos segmentos envolvidos: governo e sociedade civil. Por exemplo, na assistência social, a representação governamental na esfera federal reproduz a predominância feminina encontrada nessa área, até porque, como sugerimos, mesmo para as cadeiras reservadas aos órgãos executivos de pastas tipicamente associadas aos homens, as mulheres neles presentes tendem a ser indicadas para os conselhos da assistência social, dada a associação construída desse gênero à política social. Na representação da sociedade civil, a presença dos gêneros tende ao equilíbrio nessa escala. No meio ambiente, a pre- 
dominância masculina encontrada em todas as escalas se acentua na esfera federal, principalmente na representação da sociedade civil.

Esses dados podem ser explicados, de um lado, pelo fato de que os custos da participação são maiores para a representação da sociedade civil e eles recaem com maior intensidade no grupo das mulheres, a quem é atribuída a maior parte dos cuidados com as dimensões domésticas. Além disso, ou por isso mesmo, como vimos, mesmo sendo maioria na base de algumas organizações, como meio ambiente, as mulheres são minoria nas cadeiras dos conselhos dessa área. Os homens acabam assumindo cargos de direção e representação até porque possuem mais recursos de tempo para experimentar e ganhar aprendizado para as responsabilidades que demandam esses cargos. O problema é que essa cadeia-mais tempo, mais recursos, mais experiência - se naturaliza na ideia de que os homens são mais preparados para cargos de direção. Em muitos casos, mesmo acumulando, a custos bem maiores, a mesma experiência e aprendizado, as mulheres são preteridas para esses cargos diretivos por conta daquela naturalização.

No entanto, de outro lado, e como complemento, nosso artigo também destacou a importância de considerar o tipo de associativismo presente em cada área de política pública e que exerce a representação da sociedade civil nos respectivos conselhos. Desse modo, julgamos importante considerar que as organizações de natureza comunitária e assistencial, de predomínio feminino, não têm, na maioria dos casos, abrangência nacional, o que limita a sua capacidade de instituir representantes conselhistas para além do município. Esse fato também ajuda a entender os filtros de gênero que respondem por uma maior presença masculina nos conselhos nacionais.

Ainda no que diz respeito ao associativismo, identificamos que esta variável pode ajudar a compreender também as diferenças da presença dos gêneros nos conselhos gestores a partir da trajetória própria de alguns movimentos e organizações. No caso da saúde, por exemplo, vimos que os movimentos de mulheres que tiveram um papel importante nas reformas dessa área, desde a Constituição de 1988, não adotaram os conselhos municipais e estaduais dessas áreas como campos estratégicos de engajamento e atuação.

Por fim, no que se refere ao desenho institucional, notamos que uma composição em que predomina a representação da sociedade civil não necessariamente implica maior presença de mulheres. No entanto, 
como sugerimos, o método de escolha dos representantes desse segmento pode ter alguma influência na maior ou menor presença feminina nos conselhos, o que deve ser explorado por novas pesquisas a fim de obtermos dados mais conclusivos.

De modo geral, o conjunto de resultados decorrentes de nossa análise atende ao objetivo proposto para esta pesquisa, a qual, por conta do caráter não representativo da amostra dos conselhos estudados, buscou verificar a existência de indícios empíricos que dialogassem com proposições teóricas, dados oficiais e outras análises que não se dedicaram à verificação de relações entre o desenho institucional, a área de política pública, a esfera de governo, a ocupação das cadeiras conforme o gênero e os vínculos associativos dos conselheiros. Cumpre também destacar que, além de contribuir para a ampliação dos estudos sobre gênero e representação política em instituições participativas, os resultados, ao adensarem e combinarem fatores e variáveis analíticas podem servir, ademais, para os estudos e reflexões que estão voltados para a dimensão da inclusão política de outras minorias sociais.

(Recebido para publicação em julho de 2015)

(Reapresentado em março de 2016)

(Aprovado para publicação em abril de 2016) 


\section{Gênero e Representação Política nos Conselhos Gestores no Brasil}

\section{NOTAS}

1. Embora seja reconhecida a diversidade de gêneros, estamos tratando aqui especificamente das categorias masculino e feminino, e que foram identificadas pelos nomes das(os) conselheiras(os).

2. Cumpre notar a dificuldade que encontramos para a obtenção de tais informações dos conselhos, especialmente no âmbito municipal, uma vez que são muitos os municípios para os quais os regulamentos e demais informações acerca da composição e do funcionamento dos conselhos não se estão disponíveis para consulta online. Além disso, o contato telefônico é restrito em muitos municípios, onde também a publicação da mencionada legislação não é prática comum. Essas dificuldades se acentuaram para a região Norte do país, o que explica a sub-representação desta região em nossa amostra. Convém também ressaltar que os dados por gênero se referem apenas aos conselheiros titulares das gestões atuais dos referidos conselhos. Consideradas tais dificuldades, a coleta de informações ocorreu entre setembro de 2014 e março de 2015, de modo que os dados analisados apresentam um retrato dos referidos conselhos para este período.

3. A relação detalhada dos conselhos analisados, por área de política pública e esfera de governo, encontra-se no Anexo deste artigo.

4. A Estadic 2013 realizou um levantamento de informações referentes às administrações públicas estaduais, incluindo informações sobre os conselhos de saúde, assistência social e meio ambiente nas 27 unidades da Federação (IBGE, 2014a).

5. A escolha dos representantes do governo ocorre sempre por meio da indicação de quem está ocupando o Executivo.

6. A classificação do associativismo utilizada para efeito deste artigo merece algumas considerações. Em primeiro lugar, tal classificação procurou agrupar as associações não apenas de acordo com o seu campo de atuação, como a partir de diferenças importantes no interior dos campos. Assim, por exemplo, embora as associações socioassistenciais e assistenciais religiosas ocupem o mesmo campo (assistencial), procedemos a uma subdivisão interna tendo em vista a importância (teórica e empírica) do recorte religioso e de seus reflexos na dimensão de gênero. No caso do campo econômico, a subdivisão entre as associações do mundo do trabalho e as do tipo empresarial/patronal diferencia categorias de trabalhadores de empresas e organizações patronais. A categoria "movimentos sociais" procurou abrigar aquelas associações que se autoidentificam como tal. Já a categoria "socioambiental" apareceu, de forma importante, no mapeamento dos conselhos da área ambiental. Finalmente convém ressaltar que estamos empregando uma ideia mais abrangente de associação e que inclui, além do associativismo de tipo "voluntário" ou "secundário", organizações mais complexas e estruturadas, incluindo sindicatos, corporações, fundações, universidades, associações patronais, profissionais, grupos empresariais, entre vários outros (Warren, 2001; Lüchmann, 2014). De maneira mais objetiva, incluímos todas as organizações de caráter "não governamental". É importante destacar ainda a dificuldade em constatar o tipo de associativismo das instituições que classificamos na categoria "Sem identificação de entidade", cujos principais motivos foram ausência de identificação da sigla nas fontes de pesquisa ou identificação vaga, que não permitiu a classificação segura da entidade, como, por exemplo, nos casos em que havia "representantes de segmento dos usuários".

7. “Nas áreas de Saúde e Assistência social, a presença feminina é mais forte e distancia-se da média nacional, representando $73,7 \%$ e $71,7 \%$ do pessoal ocupado assalariado das respectivas áreas" (IBGE/Ipea, 2010:42; ênfases no original). 


\section{REFERÊNCIAS BIBLIOGRÁFICAS}

ALENCAR, Joana et al. (2013), "Participação Social e Desigualdades nos Conselhos Nacionais". Sociologias, vol.15, no 32, pp. 112-146.

ALMEIDA, Carla Cecília Rodrigues; LÜCHMANN, Lígia Helena Hahn; RIBEIRO, Ednaldo. (2012), "Associativismo e Representação Política Feminina no Brasil”. Revista Brasileira de Ciência Política, no 8, pp. 237-263.

AVELAR, Lúcia. (2013), “Movimentos, Redes, Feminismo de Estado: A Representação Extraparlamentar das Mulheres Brasileiras". Cadernos Adenauer, no 3, pp. 71-87.

BOHN, Simone. (2010), “Feminismo Estatal sob a Presidência Lula: O Caso da Secretaria de Políticas para Mulheres". Revista Debates, vol. 4, no 2, pp. 81-106.

BOLZENDAHL, Catherine; BROOKS, Clem. (2007), “Women's Political Representation and Welfare State Spending in 12 Capitalist Democracies". Social Forces, vol. 85, no 4, pp. 1509-1534.

BORBA, Julian; LÜCHMANN, Lígia Helena Hahn. (2007), “Orçamento Participativo: Uma Análise das Experiências Desenvolvidas em Santa Catarina”, in J. Borba; L. H. Lüchmann (orgs.), Orçamento Participativo: Análise das Experiências Desenvolvidas em Santa Catarina. Florianópolis, Insular, pp. 21-59.

CAIAZZA, Amy; PUTNAM, Robert. (2005), "Women's Status and Social Capital in the United States". Journal of Women, Politics, and Policy, vol. 27, nos 1-2, pp. 69-84.

COSTA, Ana Maria. (2009), "Participação Social na Conquista das Políticas de Saúde para Mulheres no Brasil”. Ciência \& Saúde Coletiva, vol. 14, no 4, pp. 1073-1083.

COSTA, Delaine Martins. (2001), “Capacitação de Líderes Femininas: Reflexões sobre a Experiência do IBAM". Revista Estudos Feministas, vol. 9, no 1, pp. 231-224.

CUNHA, Eleonora Schettini M. (2012), "Conferências de Políticas Públicas e Inclusão Participativa". Texto para Discussão nำ1733. Rio de Janeiro, Instituto de Pesquisas Econômicas Aplicadas.

IBGE (Instituto Brasileiro de Geografia e Estatística). (2010), Censo 2010. Brasília, Instituto Brasileiro de Geografia e Estatística.

. (2014a), Perfil dos Estados Brasileiros. Rio de Janeiro, Instituto Brasileiro de Geografia e Estatística.

. (2014b), Perfil de Informações Básicas Municipais. Assistência Social 2013. Rio de Janeiro, Instituto Brasileiro de Geografia e Estatística.

IBGE/IPEA (Instituto Brasileiro de Geografia e Estatística / Instituto de Pesquisa Econômica Aplicada). (2010), As Fundações Privadas e Associações sem Fins Lucrativos no Brasil. Rio de Janeiro, Instituto Brasileiro de Geografia e Estatística/Instituto de Pesquisa Econômica Aplicada.

IPEA (Instituto de Pesquisa Econômica Aplicada). (2013), Perfil dos Conselheiros Nacionais. Relatório de Pesquisa. Brasília, Instituto de Pesquisa Econômica Aplicada.

KROOK, Mona Lena. (2008), “La Adoción e Impacto de las Leyes de Cuotas de Gênero: Una Perspectiva Global", in M. R. Tobar (ed.), Mujer y Política. El Impacto de las Cuotas de Género en América Latina. Santiago, Catalonia. 


\section{Gênero e Representação Política nos Conselhos Gestores no Brasil}

LOVENDUSKI, Joni. (2005), State Feminism and Political Representation. New York, Cambridge University Press.

LÜCHMANN, Lígia Helena Hahn. (2007), “A Representação no Interior das Experiências de Participação". Lua Nova, no 70, pp. 139-170.

. (2014), “Abordagens Teóricas sobre o Associativismo e seus Efeitos Democráticos". Revista Brasileira de Ciências Sociais, vol. 29, no 85, pp. 159-178.

; ALMEIDA, Carla Cecília Rodrigues. (2010), “A Representação Política das Mulheres nos Conselhos Gestores de Políticas Públicas". Revista Katálysis, vol. 13, pp. 86-94.

MANSBRIDGE, Jane. (1999), "Should Blacks Represent Blacks and Women Represent Women? A Contingent 'yes'”. The Journal of Politics, vol. 61, no 3, pp. 628-657.

MOTA, Fernanda Ferreira; BIROLI, Flávia. (2014), “O Gênero na Política. A Construção do 'Feminino' nas Eleições Presidenciais de 2010". Cadernos Pagu, vol. 43, pp. 197-231.

NORRIS, Pippa; INGLEHART, Ronald. (2003), Gendering Social Capital: Bowling in Women's Leagues?. Trabalho apresentado na conferência Gender and Social Capital, St. John's College, University of Manitoba, 2-3 de maio.

PHILLIPS, Anne. (1991), Engendering Democracy. Cambridge, Polity.

. (2001), “De uma Política de Ideias a uma Política de Presença?". Revista Estudos Feministas, vol. 9, no 1, pp. 268-290.

PINTO, Céli R. Jardim; MORITZ, Maria Lúcia Freitas. (2009), “A Tímida Presença de Mulheres na Política Brasileira: Eleições Municipais em Porto Alegre (2008)". Revista Brasileira de Ciência Política, no 2, pp. 61-87.

SACCHET, Teresa. (2009), "Capital Social, Gênero e Representação Política no Brasil”. Opinião Pública, vol. 15, no 2, pp. 306-332.

SECRETARIA-GERAL DA REPÚBLICA. (2014), Participação Social no Brasil: Entre Conquistas e Desafios. Brasília, Secretaria-Geral da República.

TSE (Tribunal Superior Eleitoral). (2015), “Estatísticas Eleitorais 2014”. Disponível em $<$ http://www.tse.jus.br/eleicoes/estatisticas/estatisticas-eleitorais-2014- resultado $>$. Acessado em 22 de abril.

WARREN, Mark. (2001), Democracy and Association. Princeton, NJ, Princeton University Press.

WILliAMS, Melissa S. (1998), Voice, Trust, and Memory. Marginalized Groups and the Failings of Liberal Representation. New Jersey, Princeton University Press.

YOUNG, Iris Marion. (2000), Inclusion and Democracy. Oxford, Oxford University Press.

ZAREMBERG, Gisela. (2015), “¿Género versus Pueblo?: Movilización, Cooptación y Participación en Nicaragua, Venezuela, Brasil y México". [no prelo, previsto para publicação em 2016] 


\section{ANEXO}

\section{Relação dos Conselhos Gestores Mapeados}

\section{Área: Assistência Social}

\section{Federal}

Estaduais: Bahia (BA), Goiás (GO), Mato Grosso do Sul (MS), Minas Gerais (MG), Paraná (PR), Pernambuco (PE), Rio Grande do Sul (RS), Rondônia (RO), Santa Catarina (SC), São Paulo (SP) e Tocantins (TO).

Municipais: Anápolis (GO), Aparecida de Goiânia (GO), Belo Horizonte (MG), Bento Gonçalves (RS), Blumenau (SC), Campinas (SP), Cascavel (PR), Contagem (MG), Cuiabá (MT), Curitiba (PR), Dourados (MS), Florianópolis (SC), Goiânia (GO), Guarulhos (SP), Itabuna (BA), Jaboatão dos Guararapes (PE), Joinville (SC), Juiz de Fora (MG), Londrina (PR), Luziânia (GO), Maringá (PR), Novo Hamburgo (RS), Olinda (PE), Palmas (TO), Pelotas (RS), Ponta Grossa (PR), Ponta Porã (MS), Porto Alegre (RS), Recife (PE), São José (SC), São José dos Campos (SP), São Paulo (SP) e Vitória da Conquista (BA).

\section{Área: Saúde}

\section{Federal}

Estaduais: Acre, Bahia, Goiás, Mato Grosso, Mato Grosso do Sul, Paraná, Pernambuco, Rio Grande do Sul, São Paulo e Tocantins.

Municipais: Anápolis (GO), Araguaína (TO), Ariquemes (RO), Belo Horizonte (MG), Betim (MG), Blumenau (SC), Campinas (SP), Cascavel (PR), Caxias do Sul (RS), Corumbá (MS), Cuiabá (MT), Curitiba (PR), Florianópolis (SC), Goiânia (GO), Gravataí (RS), Guarulhos (SP), Imperatriz (MA), Itabuna (BA), Jaboatão dos Guararapes (PE), Ji-Paraná (RO), Joinville (SC), Londrina (PR), Manaus (AM), Maringá (PR), Novo Hamburgo (RS), Olinda (PE), Palmas (TO), Pelotas (RS), Ponta Grossa (PR), Recife (PE), Rio Branco (AC), São Bernardo do Campo (SP), Salvador (BA), Santo André (SP), São Paulo (SP), Uberlândia (MG) e Uruguaiana (RS).

\section{Área: Meio Ambiente}

\section{Federal}

Estaduais: Bahia, Maranhão, Mato Grosso, Mato Grosso do Sul, Minas Gerais, Pará, Paraná, Pernambuco, Rio Grande do Sul, São Paulo e Tocantins.

Municipais: Anápolis (GO), Aparecida de Goiânia (GO), Belo Horizonte (MG), Betim (MG), Campinas (SP), Campo Grande (MS), Caxias do Sul (RS), Curitiba (PR), Florianópolis (SC), Goiânia (GO), Guarulhos (SP), Imperatriz (MA), Itabuna (BA), Juiz de Fora (MG), Londrina (PR), Maringá (PR), Naviraí (MS), Olinda (PE), Ponta Grossa (PR), Porto Alegre (RS), Porto Velho (RO), Recife (PE), Rio Branco (AC), Rio Grande (RS), Rio Verde (GO), Santa Maria (RS), Santo André (SP), São Bernardo do Campo (SP), São Luís (MA), São Paulo (SP), Sidrolândia (MS), Sinop (MT), Uberlândia (MG) e Uruguaiana (RS). 


\section{RESUMO}

\section{Gênero e Representação Política nos Conselhos Gestores no Brasil}

Estudos sobre Conselhos Gestores de Políticas Públicas no Brasil têm buscado avaliar sua capacidade em promover inclusão política. Considerada a variação na presença feminina junto aos Conselhos, o artigo examinou 140 Conselhos Gestores das áreas da Assistência Social, Saúde e Meio Ambiente, a fim de verificar a relação entre a presença dos gêneros, o desenho institucional e o perfil do associativismo que ocupa assento nesses espaços. Os resultados apontam a relação entre área de política pública, esfera de governo, representação por segmento (governo e sociedade civil) e a maior ou menor presença feminina nesses espaços. Assim, o artigo registra e reforça a importância do cruzamento de variáveis explicativas que são decorrentes de dinâmicas e processos de cunho político-institucional e de caráter sociocultural. Em um plano mais amplo, contribui para o aprofundamento do conhecimento sobre os fatores que potencializam o incremento da representação política das mulheres nos processos decisórios no Brasil.

Palavras-chave: conselhos gestores; representação política; gênero; democracia; mulheres

\section{ABSTRACT \\ Gender and Political Representation among Brazilian Management Councils}

Studies on public policy management councils in Brazil have sought to assess their ability to promote political inclusion. In light of the varying numbers of women on the councils, this article examined 140 management councils in the areas of social welfare, health, and environment, in order to identify the relationship between the number of women on the councils, the institutional design and the presence of associations in such spaces. The results point to a relationship between the area of public policy, the sphere of government, representation according to segment (government and civil society) and the number of women in those spaces. The article therefore states and reinforces the significance of the intersection of explanatory variables derived from dynamics and processes of a political-institutional and socio-cultural nature. In a wider sense, this contributes to a deepening of knowledge on factors that favor an increase in political representation among women in decision-making processes in Brazil.

Key words: management councils; political representation; gender; democracy; women 


\section{RÉSUMÉ}

\section{Genre et Représentation Politique dans les Conseils de Gestion du Brésil}

Un certain nombre d'études sur les Conseils de gestion des politiques publiques au Brésil ont cherché à évaluer leur capacité à promouvoir l'inclusion politique. En fonction des variations relatives à la présence féminine dans les Conseils, l'article a examiné 140 Conseils de gestion des domaines de l'assistance sociale, de la santé et de l'environnement, dans le but d'analyser, dans leur composition, la relation entre la présence des femmes, la structure institutionnelle et le profil associatif. Les résultats mettent en évidence les rapports qui existent entre le domaine de politique publique, la sphère de gouvernement, la représentation collégiale (gouvernement et société civile) et la présence plus ou moins importante des femmes dans ces espaces. Cet article veut ainsi démontrer l'importance du croisement des variables explicatives procédant de dynamiques et de processus de nature politico-institutionnelle et de caractère socioculturel. Sur un plan plus général, on veut contribuer à l'approfondissement des connaissances sur les facteurs permettant l'augmentation de la représentation politique des femmes dans les processus décisionnaires du Brésil.

Mots-clés: conseils de gestion; représentation politique; genre; démocratie; femmes

\section{RESUMEN}

\section{Género y Representación Política en los Consejos Gestores en Brasil}

Los estudios sobre Consejos Gestores de Políticas Públicas en Brasil han buscado evaluar su capacidad en promover la inclusión política. Considerando la variación de la presencia femenina en los Consejos, el artículo examina 140 Consejos Gestores en las áreas de Asistencia Social, Salud y Medio Ambiente, para verificar la relación existente entre la presencia de los géneros, el diseño institucional y el perfil del asociativismo que se maneja en estos espacios. Los resultados revelan una relación entre área de política pública, esfera de gobierno, representación por segmento (gobierno y sociedad civil) y una mayor o menor presencia femenina en estos espacios. De esta manera, el artículo registra y fortalece la importancia del cruce de variables explicativas que son derivadas de dinámicas y procesos de naturaleza político-institucional y de carácter sociocultural. En un plano más amplio, contribuye a la profundización del conocimiento sobre los factores que potencializan el incremento de la representación política de las mujeres en los procesos decisorios en Brasil.

Palabras clave: consejos gestores; representación política; género; democracia; mujeres 